\title{
Renal Preservation Therapy for Renal Cell Carcinoma
}

\author{
Yichun Chiu, ${ }^{1,2}$ and Allen W. Chiü \\ ${ }^{1}$ Division of Urology, Department of Surgery, Taipei City Hospital, Zhongxiao Branch, Taipei 115, Taiwan \\ ${ }^{2}$ School of Medicine, National Yang-Ming University, Taipei 112, Taiwan
}

Correspondence should be addressed to Allen W. Chiu, whchiu@ym.edu.tw

Received 17 March 2012; Accepted 12 July 2012

Academic Editor: Frederik C. Roos

Copyright (C) 2012 Y. Chiu and A. W. Chiu. This is an open access article distributed under the Creative Commons Attribution License, which permits unrestricted use, distribution, and reproduction in any medium, provided the original work is properly cited.

Renal preservation therapy has been a promising concept for the treatment of localized renal cell carcinoma (RCC) for 20 years. Nowadays partial nephrectomy (PN) is well accepted to treat the localized RCC and the oncological control is proved to be the same as the radical nephrectomy $(\mathrm{RN})$. Under the result of well oncological control, minimal invasive method gains more popularity than the open PN, like laparoscopic partial nephrectomy (LPN) and robot assisted laparoscopic partial nephrectomy (RPN). On the other hand, thermoablative therapy and cryoablation also play an important role in the renal preservation therapy to improve the patient procedural tolerance. Novel modalities, but limited to small number of patients, include high-intensity ultrasound (HIFU), radiosurgery, microwave therapy (MWT), laser interstitial thermal therapy (LITT), and pulsed cavitational ultrasound (PCU). Although initial results are encouraging, their real clinical roles are still under evaluation. On the other hand, active surveillance (AS) has also been advocated by some for patients who are unfit for surgery. It is reasonable to choose the best therapeutic method among varieties of treatment modalities according to patients' age, physical status, and financial aid to maximize the treatment effect among cancer control, patient morbidity, and preservation of renal function.

\section{Introduction}

With the improvement of the detection modalities (ultrasound, high-quality computed tomography, etc.), the cases of small renal mass (SRMs) increased. In imaging study, $20 \%$ highly suspected renal malignancy would be finally proved as benign pathology after operation. On the other hand, studies proved that the more remaining kidney tissue we have, the lower prevalence the chronic kidney disease (CKD) would happen. Thus treatment gradually focused on the renal preservation therapy. To treat the patients with SRMs, three factors should be balanced: patient morbidity, preservation of renal function, and cancer control. In surgical part, nephron-sparing surgery (NSS)/partial nephrectomy (PN) have evolved from the treatment option to the standard management for small renal masses, have been shown to have equivalent oncological efficacy as radical nephrectomy $(\mathrm{RN})$, while reducing the prevalence of the subsequent renal insufficiency. With the same oncological control, the goal of current surgical intervention is to decrease the risk of CKD. Preservation of renal function may be associated with improved survival and avoided of the risk of cardiovascular death. In ablative therapy, radiofrequency ablation (RFA), and cryoablation (CA) remained the role for high-risk group to reduce interventional morbidity. Active surveillance also play an role for the elderly, or high-risk patients, who are unfit for further intervention.

\section{What Is the Role of Active Surveillance (AS)?}

Urologists usually ask why AS for small renal tumors. The incidence of renal cancer increased, and they caused the medical fees expansion. Despite increasing surgeries were performed, the mortality rate for all renal tumors still increased [1]. Two questions must be taken into consideration now: are we treating more SRMs without impacting on mortality? Are we overtreating the harmless renal tumors? Hollingsworth et al. had analyzed the competing-cause mortality after the surgery of kidney cancer, they found $5 \%$ cancer-specific death (CSD) within 5 years in renal 
cancer smaller than $4 \mathrm{~cm}$ and 18\% CSD in the group with size larger than $4 \mathrm{~cm}$. Despite surgical therapy, competingcause mortality for patients with renal masses rises with patients' increasing age. After 5 years, $28 \%$ elderly patients ( $>$ or $=70$ years) will die from other causes, suggesting the need for prospective studies to evaluate the role of active surveillance as an initial therapeutic approach for some SRMs [2]. What is the nature of SRMs? Only $10-30 \%$ renal masses regardless of the size are benign, but tumors in the elderly and SRMs are more likely to be benign [3]. Imaging modalities especially multidetector computed tomography (MDCT) scan revealed $>90 \%$ accuracy of detection for RCC. But it is still controversial to distinguish between RCC and benign in growth or tumor size at presentation. 10\% of SRMs $<3 \mathrm{~cm}$ are pT3 and aggressiveness increased significantly when the renal tumor beyond $3 \mathrm{~cm}$, but most SRMs are pT1 [4]. Renal biopsy is currently proved safe and low risk of tumor seeding even with the method of core biopsy. 92\% biopsy result was conclusive. Thus renal tumor biopsy is suggested if the result may change the treatment policy such as lymphoma, metastasis of other cancer, or benign lesion [5].

Age and Charlson score (not treatment type) impacted overall survival on the study with multivariate analysis, and cardiovascular events were usually a leading cause of mortality, driven by chronic renal failure (CRF) [15]. It should be considered if the patient will have the probability to die of the other unrelated disease. Baseline clinical characteristics of SRMs do not allow to reliably predict the clinical outcome but available AS studies showed the chance of progression and metastasis is low in these selected cases $(0.9 \%-1.3 \%)$. CT and MRI are thought to be more accurate in determining size variations and expert opinion advises $6 \sim 12$ months interval as the optimal compromise between oncological safety and the risk of radiation exposure and kidney function morbidity due to contrast medium. Usually significant proportion of SRMs (30\%) do not grow at all and the average grow is slow $(0.15-0.3 \mathrm{~cm} /$ year $)$, but if any growth up to $4 \mathrm{~cm}$ and doubling time of SRM volume $<12$ months are considered to terminate AS. Current SRM studies under AS disclosed small risk of progression (1$2 \%)$, who progress "tend" to grow faster and almost all death are noncancer related [16-20]. No clinically relevant tumor marker could help the AS now. Patients should know the following issues: SRMs are most malignant and RCC is life threatening. The aggressiveness cannot be precisely predicted. Growth rate does not predict malignancy and some SRM will show fast growth and aggressive behavior during surveillance. They also should know possible window of opportunity for NSS may be lost, and loss the opportunity of cure if metastases occur.

Active surveillance is a reasonable option for patients with limited life expectancy or for those who are unfit for or do not desire intervention. In the future, it will be helpful to know more about the natural history of untreated small renal masses. Developing inclusion and termination criteria is important to decrease the calculated risk of the cancer progression.

\section{Ablative Therapy in Renal Preservation Therapy: Now and the Future? [Table 1]}

Though the partial nephrectomy is the standard treatment for SRMs, the overall complication rate is around $20 \%$. Thus less invasive percutaneous or laparoscopic ablation therapy such as cryoablation (CA) and radiofrequency ablation (RFA) are developed to be an alternative of surgical resection. The American Urological Association (AUA) guidelines regard the thermal ablation as the choice for the surgical high-risk patients who still wants to receive active treatment and accepts the need for long-term radiographic surveillance [21]. European Association of Urology (EAU) guidelines consider this modalities for the patients with SRMs and/or significant comorbidity who are unfit for surgery [22]. In these two famous guidelines, we could conclude that in patients with SRMs smaller $4 \mathrm{~cm}$ who are not suitable for PN (the elder or high comorbidity) or some cases with hereditary RCC (VHL syndrome), the ablative therapy is indicated.

Both CA and RFA could be done by laparoscopic or percutaneous (Perc) method. CA causes irreversible cell death at $-70^{\circ} \mathrm{C}$ and RFA makes cell death and tissue coagulation with heating over $60^{\circ} \mathrm{C}$ The ideal mass to ablate is solid/enhancing and peripheral/exophytic mass, and the challenging cases were endophytic, hilar, and upper pole mass. Renal biopsy should be taken irrespective of technique and technology and choice of technique should be based on the situation and morphology of renal mass and patient comorbidity. The ideal case for laparoscopic approach is tumor in the anterior valve, upper pole and medial tumor nearby the ureter; good candidate for percutaneous ablation is the tumor in posterior valve, endophytic central and hilar area. The trend is to perform percutaneous method if you could do both of them.

In the current studies, cryoablation may have similar efficacy and complication rate as RFA [23]. The surgical (mainly laparoscopic, LCA) approach allows placement of cryotherapy probes into the lesions under direct vision. Realtime visual and continuous ultra sonographic monitoring provides precise control of the ice ball formation and extension. LCA is better to approach anterior and medical lesions to avoid of nearby tissue injury, but patients still need to receive general anesthesia $(\mathrm{GA})$ and inherent risks of surgical exploration and dissection. Percutaneous CA (PCA) is ideal for posterior lesion and usually could be performed under sedation/local anaesthesia [24]. Comparing with PN, LCA results in higher risk of local tumor progression but a lower risk of perioperative complication [14]. No significant differences in efficacy were found between these two ablative techniques (RFA and CA) [23]. A problem arise from the ablation therapy is that correct pathology diagnosis could be missed due to the limited obtained tissue. Policy for followup after ablation is important no matter what kind of imaging modalities with or without biopsy. In cross sectional imaging, we need confirm absence of enhancement; CA lesion often shrinks with time but RF lesion may not shrink. Follow-up imaging studies are suggested in 3-6 and 12 months. Biopsy is suggested in case with suspicion 
TABLE 1: Mid- to long-term results of cryoablation (CA) and radiofrequency (RF), and one group compared the results between radiofrequency and partial nephrectomy $(\mathrm{PN})$.

\begin{tabular}{|c|c|c|c|c|c|c|c|}
\hline & Method & Approach & RCC numbers & $\begin{array}{l}\text { Mean followup } \\
\text { (months) }\end{array}$ & Local recurrence & Relapse free survival & $\begin{array}{c}\text { Cancer specific } \\
\text { survival }\end{array}$ \\
\hline McDougal et al. [6] & $\mathrm{RF}$ & $\mathrm{P}$ & 20 & 55 & 1 & $94 \%$ & $100 \%$ \\
\hline Levinson et al. [7] & $\mathrm{RF}$ & $\mathrm{P}$ & 18 & 62 & 3 & $81 \%$ & $100 \%$ \\
\hline Tracy et al. [8] & $\mathrm{RF}$ & $\mathrm{P}, \mathrm{L}, \mathrm{O}$ & 53 & 53 & 5 & $91 \%$ & $99 \%$ \\
\hline Davol et al. [9] & CA & $\mathrm{L}, \mathrm{O}$ & 34 & 64 & 5 & $84 \%$ & $100 \%$ \\
\hline Weld et al. [10] & CA & $\mathrm{L}$ & 22 & 46 & 0 & $100 \%$ & $100 \%$ \\
\hline Aron et al. [11] & CA & $\mathrm{L}$ & 55 & 95 & 7 & $87 \%$ & $89 \%$ \\
\hline Guazzoni et al. [12] & CA & $\mathrm{L}$ & 44 & 61 & 0 & $100 \%$ & $100 \%$ \\
\hline Beemster et al. [13] & CA & $\mathrm{L}$ & 51 & 30 & 3 & $94.4 \%$ & $100 \%$ \\
\hline \multirow[t]{2}{*}{ Olweny et al. [14] } & $\mathrm{RF}$ & $\mathrm{P}, \mathrm{L}$ & 37 & 78 & 3 & $91.7 \%$ & $97.2 \%$ \\
\hline & $\mathrm{PN}$ & $\mathrm{L}, \mathrm{O}$ & 37 & 73 & 3 & $94.6 \%$ & $100 \%$ \\
\hline
\end{tabular}

RCC: renal cell carcinoma; RF: radiofrequency; CA: cryoablation; P: percutaneous; L: laparoscopy; O: open; PN: partial nephrectomy.

of recurrence. In report from seven USA medical centers, the recurrence rate after RFA is $13.4 \%$ and CA is $3.9 \%$. 2 -year overall survival rate is $82.5 \%$ and disease-free survival is $97.4 \%$ [25]. Selection bias should be overcome for the future study comparing ablation therapy to PN. Ablation is accepted as therapy for SRMs with both short- and intermediate-term oncological efficacy [26], and long-term data is promising but limited $[7,8,10-12]$. Overall major complication rate $0.8-4 \%$ (higher in Perc RFA) and minor complication rate $0.8-4 \%$ (higher in LCA) were reported [27]. Surgical salvage after failed thermal ablation have be proved challenging and could result in radical nephrectomy. In conclusion, thermoablative therapy and cryoablation are reasonable options for patients who are unfit for surgery with small renal tumors $(<4 \mathrm{~cm})$ and they play an important role in the renal preservation therapy to improve the patient procedural tolerance. Technique selection should be based on anatomical tumor characteristics. Followup consists on regular cross-sectional imaging as success is currently a proxy for "absence of enhancement." major complication rate is acceptable and do not differ between techniques and technologies. Long-term oncological results are limited and no difference for LCA, LRF, and PRF. Because most ablative therapy is used on the patients with elder age and high risk, some patients will possibly die before the recurrence happens and loss of followup. It is challenging to compare the results between ablative therapy and partial nephrectomy. Table 1 summarized the mid to long term results of CA and RF. And Olweny et al. compared the results between RF and PN [14].

Novel modalities but limited to small number of patients include high-intensity ultrasound (HIFU), radiosurgery, microwave therapy (MWT), laser interstitial thermal therapy (LITT), and pulsed cavitational ultrasound (PCU). They are still under evaluation [21,33-36].

\section{What Is the Role of Partial Nephrectomy: Past, Now, and the Future? [Table 2]}

In recent years, the management of localized kidney tumors has changed, resulting in a shift away from radical nephrectomy (RN) toward a more frequent use of partial nephrectomy (PN). Open partial nephrectomy (OPN) has already become the standard of care in the treatment of renal masses smaller than $4 \mathrm{~cm}$ as well as select tumors up to $7 \mathrm{~cm}$. The 5-year cancer-specific survival rate of partial nephrectomy had been proved more than $95 \%$, almost the same as radical nephrectomy [37]. In additional to providing equivalent oncological control, the preservation of healthy kidney increased the overall survival rate and decreased comorbid disease. But bleeding, positive surgical margin (PSM) still raised some discussion. In 1993, laparoscopic partial nephrectomy (LPN) was first reported by Winfield et al. [38] and McDougall et al. [39]. The criticize at then is its challenging technique and long learning curve. But with the improved laparoscopic surgical instrument, this minimal invasive approach could also achieve equivalent outcome with OPN and lower morbidity profile (less operative time, decreased blood loss, and a shorter hospital stay) [28]. Gill et al. found an overall complication rate of $18.6 \%$ for LPN across all patients, with a complication decreasing from $22.1 \%$ for initial procedures to $8.5 \%$ for the procedures after the learning curve had been reached. They performed 800 LPN and concluded as the following: results will improve with experiences, warm ischemia time (WIT) will reduce down 14.4 minutes (initially 31 minutes), but with the earlier removal of the hilar clamp will increased estimated blood loss (EBL) and blood transfusion [29]. But not all the urologist could do 800 laparoscopic partial nephrectomies in all his life. Every minute counts when the renal hilum is clamped during partial nephrectomy [40]. Ordinary WIT is 
TABLE 2: Main series of minimal invasive partial nephrectomy (laparoscopic or/and robot assisted laparoscopic method).

\begin{tabular}{|c|c|c|c|c|c|c|c|c|}
\hline \multirow{3}{*}{$\begin{array}{l}\text { Method } \\
\text { Number }\end{array}$} & \multirow{2}{*}{\multicolumn{3}{|c|}{$\begin{array}{c}\text { Gill et al. }[28,29] \\
\text { LPN }\end{array}$}} & \multirow{3}{*}{$\begin{array}{c}\text { Benway et al. [30] } \\
\text { RPN } \\
183\end{array}$} & \multirow{2}{*}{\multicolumn{2}{|c|}{$\begin{array}{c}\text { Dulabon et al. [31] } \\
\text { RPN }\end{array}$}} & \multicolumn{2}{|c|}{ Long et al. [32] } \\
\hline & & & & & & & \multirow{2}{*}{$\frac{\text { LPN }}{182}$} & \multirow{2}{*}{$\frac{\mathrm{RPN}}{199}$} \\
\hline & 276 & 289 & 235 & & 51 & 405 & & \\
\hline & $99 \sim 03$ & $04 \sim 06$ & $07 \sim 08$ & & Hilar & nonhilar & \multicolumn{2}{|c|}{ Complex tumors (RENAL score $>7$ ) } \\
\hline Size $(\mathrm{cm})$ & 3.0 & 2.9 & 3.3 & 2.87 & 3.2 & 2.6 & 4.0 & 3.8 \\
\hline OP Time (minutes) & 202 & 235 & 250 & 210 & 195 & 187 & 241 & 197 \\
\hline $\mathrm{EBL}(\mathrm{mL})$ & 242 & 245 & 373 & 132 & 262 & 208 & 325 & 280 \\
\hline WIT (minutes) & 31.9 & 31.6 & 14.1 & 23.9 & 26.3 & 19.6 & 23.2 & 22.4 \\
\hline Complication & $23.9 \%$ & $14.9 \%$ & $10.6 \%$ & $8.2 \%$ & $2.4 \%$ & $5.2 \%$ & $4.9 \%$ & $5.5 \%$ \\
\hline Transfusion & $14.1 \%$ & $8.7 \%$ & $15.3 \%$ & $1 \%$ & $2.4 \%$ & $4.2 \%$ & $14.3 \%$ & $12.1 \%$ \\
\hline
\end{tabular}

LPN: laparoscopic partial nephrectomy; RPN: robot assisted laparoscopic partial nephrectomy; OP time: operative time; EBL: estimated blood loss; WIT: warm ischemia time; RENAL nephrometry score: to quantify the anatomical characteristics of renal masses on computerized tomography or magnetic resonance imaging.

suggested below 30 minutes but recent recommendation is less than 20 minutes [41]. "Zero ischemia" and "selectiveclamping" technique were introduced to decrease the effect of WIT but both of them are technically dependent [42, 43]. In 2004, Gettman et al. first described robot assisted laparoscopic partial nephrectomy (RPN) [44]. RPN had foreshortened the learning curve than LPN. It was a big barrier from OPN to LPN because of the warm ischemia time (WIT) and the positive surgical margin (PSM). With the improvement of laparoscopic surgical modalities, intraoperative ultrasound, tissue glue/sealant, improvement of stitches material (barbed suture), high-coagulation energy, slidingclip renorrhaphy, robot for reconstruction, and minimally invasive approaches for $\mathrm{PN}$ have been rapidly gaining popularity. RPN makes intracorporeal suturing easier even for subspecialized surgeons. Contemporary series show RPN provides equal functional and oncological outcome [30, 31]. In conclusion, partial nephrectomy is the mainstream treatment in the surgical part for renal preservation therapy, current trend is from open PN to minimal invasive PN with equal oncological control and less surgical morbidity. Ischemia time should be limited less than 20 minutes, but LPN is technique challenging and reserved only to experienced centers. RPN shortens the learning for the laparoscopic approach method; the midterm result disclosed the equal functional and oncological control [45]. But the cost is the core problem of RPN. It is no doubt that high technology leads the trend of partial nephrectomy, preferably with laparoscopic approach in experienced hands.

\section{Conclusion}

Surgery is still the gold standard in the management of SRMs. Nephron sparing surgery (NSS)/partial nephrectomy (PN) is the best option whenever it could be used. RFA/CA are reasonable options for those old and high-risk patients that till wish active treatment for SRMs. New modality like HIFU is still under evaluation. Active surveillance (AS) should be restricted to the patients with high-surgical risk, elderly, infirm or who refuses surgery. For NSS/PN, evolution is from open partial nephrectomy (OPN) to minimal invasive treatment (LPN, RPN). It is reasonable to choose the best therapeutic method among varieties of treatment modalities according to patients' age, physical status, and financial aid to maximize the treatment effect among cancer control, patient morbidity, and preservation of renal function.

\section{References}

[1] J. M. Hollingsworth, D. C. Miller, S. Daignault, and B. K. Hollenbeck, "Rising incidence of small renal masses: a need to reassess treatment effect," Journal of the National Cancer Institute, vol. 98, no. 18, pp. 1331-1334, 2006.

[2] J. M. Hollingsworth, D. C. Miller, S. Daignault, and B. K. Hollenbeck, "Five-year survival after surgical treatment for kidney cancer: a population-based competing risk analysis," Cancer, vol. 109, no. 9, pp. 1763-1768, 2007.

[3] R. A. Rendon and M. A. S. Jewett, "Expectant management for the treatment of small renal masses," Urologic Oncology, vol. 24 , no. 1, pp. 62-67, 2006.

[4] M. Remzi, M. Özsoy, H. C. Klingler et al., "Are small renal tumors harmless? Analysis of histopathological features according to tumors $4 \mathrm{Cm}$ or less in diameter," Journal of Urology, vol. 176, no. 3, pp. 896-899, 2006.

[5] A. T. Wang, J. K. Wang, V. M. Montori, and M. H. Murad, "Comparative effectiveness research in urology," World Journal of Urology, vol. 29, no. 3, pp. 277-282, 2011.

[6] W. S. McDougal, D. A. Gervais, F. J. McGovern, and P. R. Mueller, "Long-term followup of patients with renal cell carcinoma treated with radio frequency ablation with curative intent," Journal of Urology, vol. 174, no. 1, pp. 61-63, 2005.

[7] A. W. Levinson, L. M. Su, D. Agarwal et al., "Long-term oncological and overall outcomes of percutaneous radio frequency ablation in high risk surgical patients with a solitary small renal mass," Journal of Urology, vol. 180, no. 2, pp. 499504, 2008.

[8] C. R. Tracy, W. Kabbani, and J. A. Cadeddu, "Irreversible electroporation (IRE): a novel method for renal tissue ablation," British Journal of Urology International, vol. 107, no. 12, pp. 1982-1987, 2011.

[9] P. E. Davol, B. R. Fulmer, and D. B. Rukstalis, "Long-term results of cryoablation for renal cancer and complex renal masses," Urology, vol. 68, no. 1, pp. 2-6, 2006. 
[10] K. J. Weld, R. S. Figenshau, R. Venkatesh et al., "Laparoscopic cryoablation for small renal masses: three-year follow-up," Urology, vol. 69, no. 3, pp. 448-451, 2007.

[11] M. Aron, K. Kamoi, E. Remer, A. Berger, M. Desai, and I. Gill, "Laparoscopic renal cryoablation: 8-year, single surgeon outcomes," Journal of Urology, vol. 183, no. 3, pp. 889-895, 2010.

[12] G. Guazzoni, A. Cestari, N. Buffi et al., "Oncologic results of laparoscopic renal cryoablation for clinical T1a tumors: 8 years of experience in a single institution," Urology, vol. 76, no. 3, pp. 624-629, 2010.

[13] P. W. T. Beemster, K. Barwari, C. Mamoulakis, H. Wijkstra, J. J. M. C. H. De La Rosette, and M. P. Laguna, "Laparoscopic renal cryoablation using ultrathin 17-gauge cryoprobes: mid-term oncological and functional results," British Journal of Urology International, vol. 108, no. 4, pp. 577-582, 2011.

[14] E. O. Olweny, S. K. Park, Y. K. Tan, S. L. Best, C. Trimmer, and J. A. Cadeddu, "Radiofrequency ablation versus partial nephrectomy in patients with solitary clinical T1a renal cell carcinoma: comparable oncologic outcomes at a minimum of 5 years of follow-up," European Urology, vol. 61, pp. 1156$1161,2012$.

[15] B. R. Lane, R. Abouassaly, T. Gao et al., "Active treatment of localized renal tumors may not impact overall survival in patients aged 75 years or older," Cancer, vol. 116, no. 13, pp. 3119-3126, 2010.

[16] M. A. S. Jewett, K. Mattar, J. Basiuk et al., "Active surveillance of small renal masses: progression patterns of early stage kidney cancer," European Urology, vol. 60, no. 1, pp. 39-44, 2011.

[17] R. J. Mason, M. Abdolell, G. Trottier et al., "Growth kinetics of renal masses: analysis of a prospective cohort of patients undergoing active surveillance," European Urology, vol. 59, no. 5, pp. 863-867, 2011.

[18] J. C. Rosales, G. Haramis, J. Moreno et al., "Active surveillance for renal cortical neoplasms," Journal of Urology, vol. 183, no. 5, pp. 1698-1702, 2010.

[19] P. L. Crispen, R. Viterbo, S. A. Boorjian, R. E. Greenberg, D. Y. T. Chen, and R. G. Uzzo, "Natural history, growth kinetics, and outcomes of untreated clinically localized renal tumors under active surveillance," Cancer, vol. 115, no. 13, pp. 2844-2852, 2009.

[20] R. Abouassaly, B. R. Lane, and A. C. Novick, "Active surveillance of renal masses in elderly patients," Journal of Urology, vol. 180, no. 2, pp. 505-509, 2008.

[21] A. C. Mues and J. Landman, "Small renal masses: current concepts regarding the natural history and reflections on the American Urological Association guidelines," Current Opinion in Urology, vol. 20, no. 2, pp. 105-110, 2010.

[22] B. Ljungberg, N. C. Cowan, D. C. Hanbury et al., "EAU guidelines on renal cell carcinoma: the 2010 update," European Urology, vol. 58, no. 3, pp. 398-406, 2010.

[23] R. El Dib, N. J. Touma, and A. Kapoor, "Cryoablation vs radiofrequency ablation for the treatment of renal cell carcinoma: a meta-analysis of case series studies," British Journal of Urology International, vol. 110, no. 4, pp. 510-516, 2012.

[24] C. J. Long, A. Kutikov, D. J. Canter et al., "Percutaneous vs surgical cryoablation of the small renal mass: is efficacy compromised?" British Journal of Urology International, vol. 107, no. 9, pp. 1376-1380, 2011.
[25] S. F. Matin, K. Ahrar, J. A. Cadeddu et al., "Residual and recurrent disease following renal energy ablative therapy: a multi-institutional study," Journal of Urology, vol. 176, no. 5, pp. 1973-1977, 2006.

[26] D. A. Kunkle and R. G. Uzzo, "Cryoablation or radiofrequency ablation of the small renal mass: a meta-analysis," Cancer, vol. 113, no. 10, pp. 2671-2680, 2008.

[27] P. Gontero, S. Joniau, A. Zitella et al., "Ablative therapies in the treatment of small renal tumors: how far from standard of care?" Urologic Oncology, vol. 28, no. 3, pp. 251-259, 2010.

[28] I. S. Gill, L. R. Kavoussi, B. R. Lane et al., "Comparison of 1,800 laparoscopic and open partial nephrectomies for single renal tumors," Journal of Urology, vol. 178, no. 1, pp. 41-46, 2007.

[29] I. S. Gill, K. Kamoi, M. Aron, and M. M. Desai, " 800 laparoscopic partial nephrectomies: a single surgeon series," Journal of Urology, vol. 183, no. 1, pp. 34-42, 2010.

[30] B. M. Benway, S. B. Bhayani, C. G. Rogers et al., "Robotassisted partial nephrectomy: an international experience," European Urology, vol. 57, no. 5, pp. 815-820, 2010.

[31] L. M. Dulabon, J. H. Kaouk, G. P. Haber et al., "Multiinstitutional analysis of robotic partial nephrectomy for hilar versus nonhilar lesions in 446 consecutive cases," European Urology, vol. 59, no. 3, pp. 325-330, 2011.

[32] J.-A. Long, R. Yakoubi, B. Lee et al., "Robotics versus laparoscopic partial nephrectomy for complex tumors: comparison of perioperative outcomes," European Urology, vol. 61, pp. 1257-1262, 2012.

[33] K. U. Köhrmann, M. S. Michel, J. Gaa, E. Marlinghaus, and P. Alken, "High intensity focused ultrasound as noninvasive therapy for multilocal renal cell carcinoma: case study and review of the literature," Journal of Urology, vol. 167, no. 6, pp. 2397-2403, 2002.

[34] A. Häcker, D. Dinter, M. S. Michel, and P. Alken, "Highintensity focused ultrasound as a treatment option in renal cell carcinoma," Expert Review of Anticancer Therapy, vol. 5, no. 6, pp. 1053-1059, 2005.

[35] S. N. Chawla, P. L. Crispen, A. L. Hanlon, R. E. Greenberg, D. Y. T. Chen, and R. G. Uzzo, "The natural history of observed enhancing renal masses: meta-analysis and review of the world literature," Journal of Urology, vol. 175, no. 2, pp. 425-431, 2006.

[36] G. Orgera, M. Krokidis, L. Monfardini et al., "Ultrasoundguided high-intensity focused ultrasound (USgHIFU) ablation in pancreatic metastasis from renal cell carcinoma," CardioVascular and Interventional Radiology. In press.

[37] P. Russo, "Oncological outcomes of partial nephrectomy for renal carcinoma greater than $4 \mathrm{~cm}$," Current Opinion in Urology, vol. 21, no. 5, pp. 362-367, 2011.

[38] H. N. Winfield, J. F. Donovan, A. S. Godet, and R. V. Clayman, "Laparoscopic partial nephrectomy: initial case report for benign disease," Journal of Endourology, vol. 7, no. 6, pp. 521526, 1993.

[39] E. M. McDougall, R. V. Clayman, P. S. Chandhoke et al., "Laparoscopic partial nephrectomy in the pig model," Journal of Urology, vol. 149, no. 6, pp. 1633-1636, 1993.

[40] R. H. Thompson, B. R. Lane, C. M. Lohse et al., "Every minute counts when the renal hilum is clamped during partial nephrectomy," European Urology, vol. 58, no. 3, pp. 340-345, 2010.

[41] F. Becker, H. Van Poppel, O. W. Hakenberg et al., "Assessing the impact of ischaemia time during partial nephrectomy," European Urology, vol. 56, no. 4, pp. 625-635, 2009. 
[42] M. S. Eisenberg, M. B. Patil, D. Thangathurai, and I. S. Gill, "Innovations in laparoscopic and robotic partial nephrectomy: a novel "zero ischemia" technique," Current Opinion in Urology, vol. 21, no. 2, pp. 93-98, 2011.

[43] D. P. Viprakasit, H. O. Altamar, N. L. Miller, and S. D. Herrell, "Selective renal parenchymal clamping in robotic partial nephrectomy: initial experience," Urology, vol. 76, no. 3, pp. 750-753, 2010.

[44] M. T. Gettman, M. L. Blute, G. K. Chow, R. Neururer, G. Bartsch, and R. Peschel, "Robotic-assisted laparoscopic partial nephrectomy: technique and initial clinical experience with daVinci robotic system," Urology, vol. 64, no. 5, pp. 914-918, 2004.

[45] G. Spana, G. P. Haber, L. M. Dulabon et al., "Complications after robotic partial nephrectomy at centers of excellence: multi-institutional analysis of 450 cases," Journal of Urology, vol. 186, no. 2, pp. 417-421, 2011. 


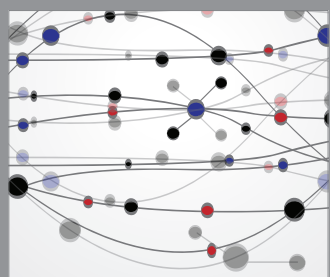

The Scientific World Journal
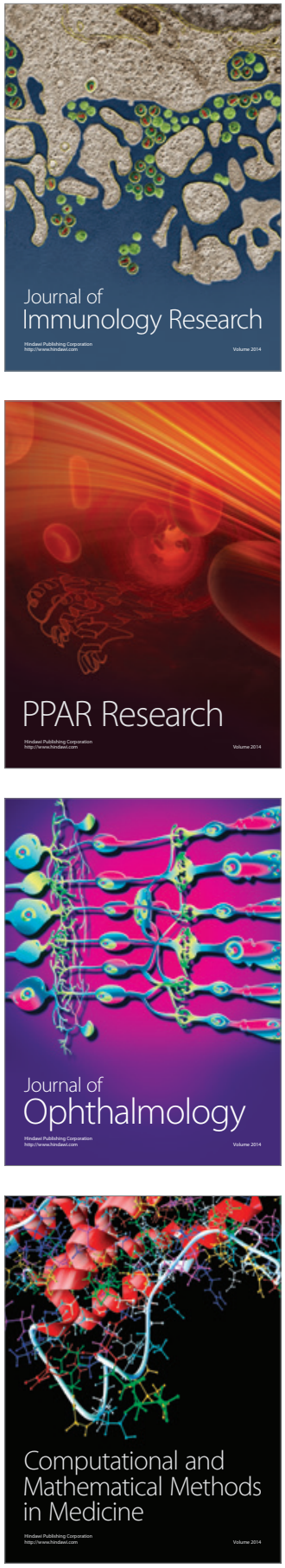

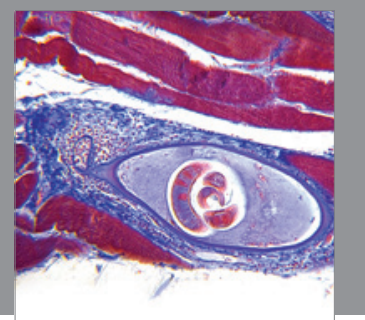

Gastroenterology

Research and Practice
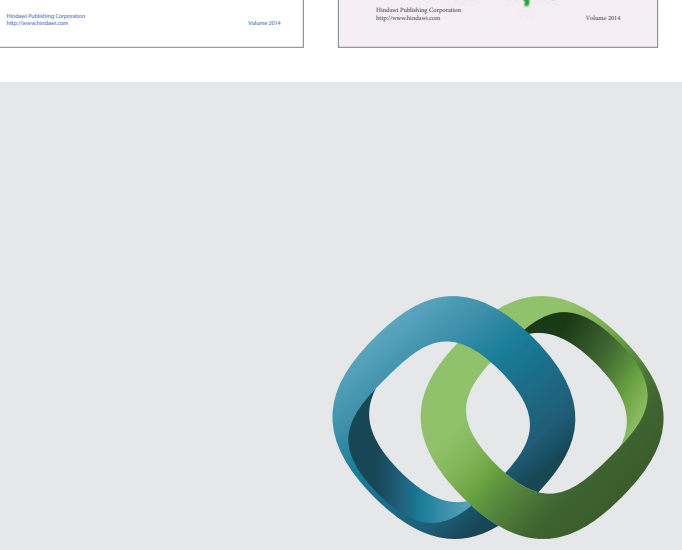

\section{Hindawi}

Submit your manuscripts at

http://www.hindawi.com
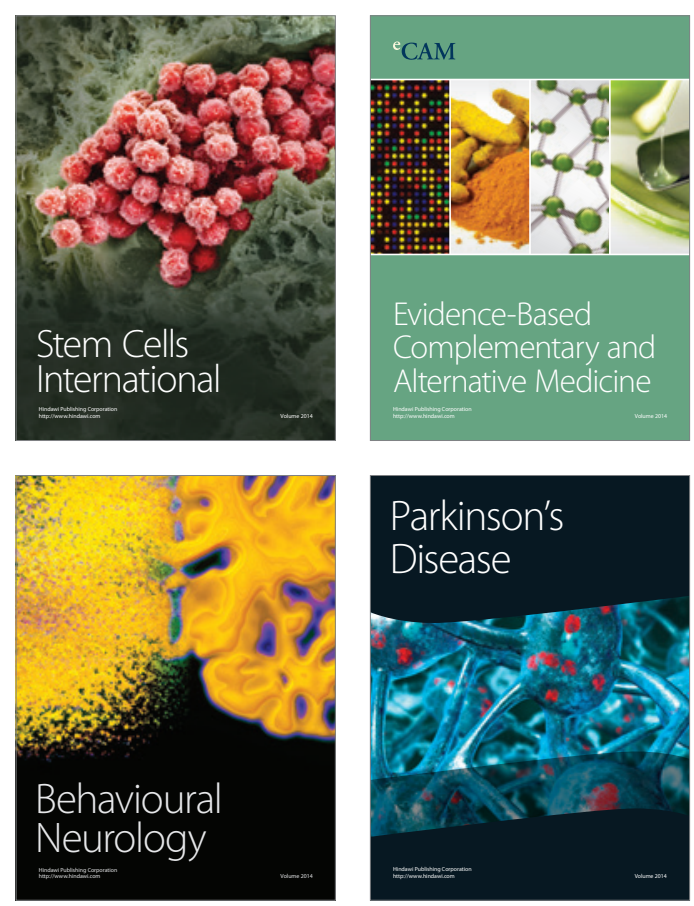

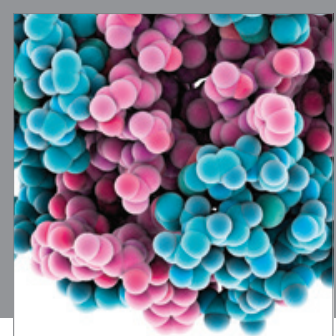

Journal of
Diabetes Research

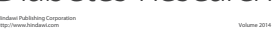

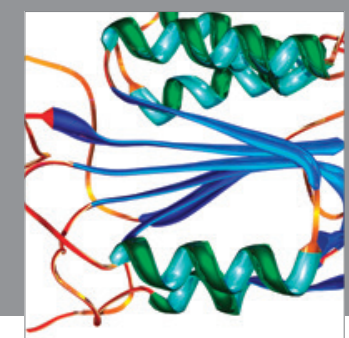

Disease Markers
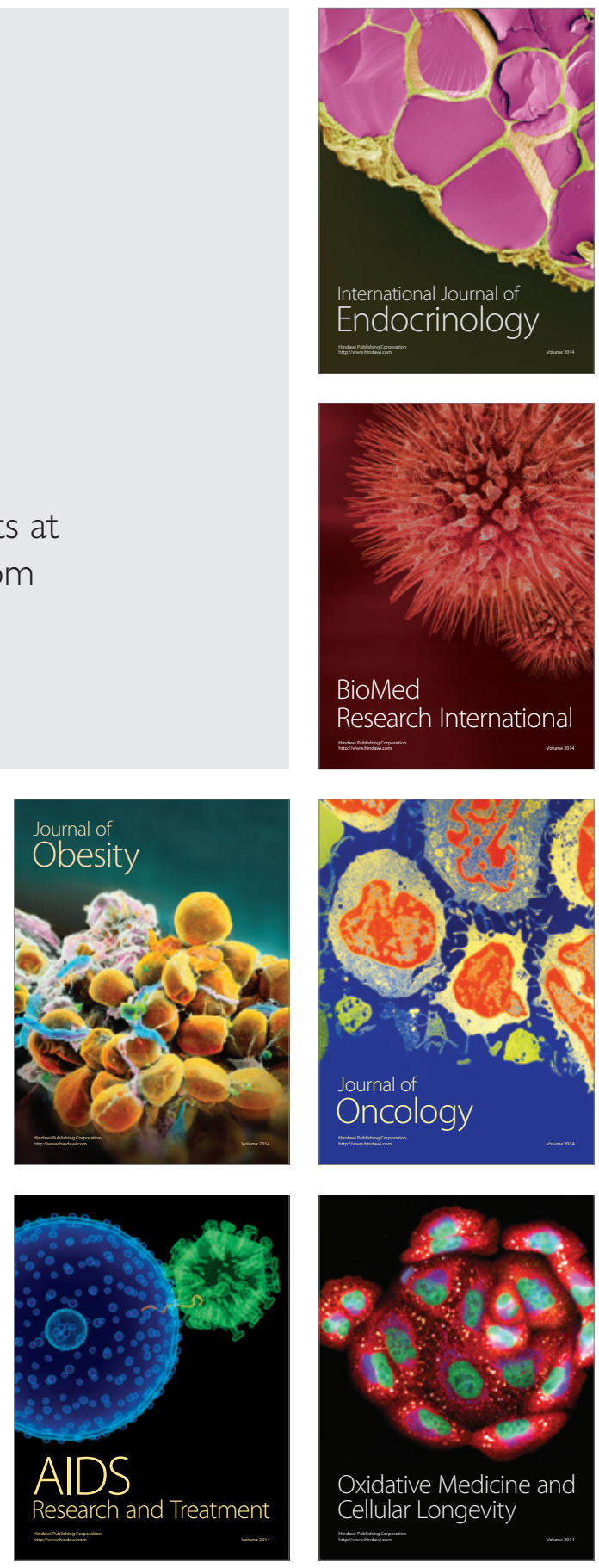